\title{
The Development Process Model of Sports Fan Loyalty via CSR of Professional Sports Teams*
}

\author{
Jaehyuk CHA ${ }^{* *}$, Hwan-Yeol LEE***, Won Jae SEO*****
}

Received: June 05, 2020 Revised: June 10, 2020 Accepted: June 19, 2020.

\begin{abstract}
Purpose: The purpose of this study is to investigate how sports fans' loyalty is built via CSR activities of professional sports teams. Furthermore, the study sought to suggest the model presenting the process of developing loyalty of sport fans by teams' CSR performance. Research design, data, and methodology: For this purpose, a survey was conducted on 450 professional sports fans through the convenience sampling method. A total of 357 of the data were used for the final analysis. Based on the collected data, frequency analysis, reliability analysis, confirmatory factor analysis, and structural equation model analysis were conducted. Results: The results showed that CSR activities contribute to building a positive image of team. Regarding fan identification, team image has also a positive effect on enhancing identification. The finding has supported the notion that attitudinal loyalty is enhanced by fan identification and further attitudinal loyalty significantly influences behavioural loyalty of fans. Conclusions: The results of this study explored the function of CSR of the teams on attitudinal and behavioural outcomes, loyalty. Moreover, the study suggested the constructual model presenting its role on enhancing fans' attitudes and behaviour affecting participation and consumption. Academic and practical implications were discussed for sport marketers and practitioners.
\end{abstract}

Keywords: CSR Activities, Team Image, Fan Identification, Attitudinal Loyalty, Behavioural Loyalty JEL Classifications: L16, L22, M3, M13, M31

\section{1. 서론}

최근 프로스포츠 산업 내에서도 스포츠 구단의 사회적 책임활동에 대한 요구가 높아지고 있다. 여기에는 그간 스포 츠 경기라는 상품을 소비하는 데 있어 스포츠 팬들이 최우선 하던 가치가 자신이 응원하는 구단의 승리라는 결과인 것 에 반해 최근에는 그보다 상품을 소비하는 과정에서의 경험을 중요시하는 가치 지향적 소비로 그 형태가 변화했기 때 문이라는 견해가 설득력 있게 제시되고 있다(Kim \& Lee, 2009). 이러한 변화는 프로스포츠 구단이 존재의 본질적이고 근원적인 목적인 승리와 이윤 추구 활동 외에도 부가적인 사회적 책임활동을 수행함으로써 스포츠 팬의 긍정적 반응을 이끄는 것이 중요해졌음을 의미한다.

스포츠 팬의 증가는 입장 수익, 중계권료, 스폰서십, 라이선스 판매 등 구단의 판매수익에 직결되기 때문에 프로스포 츠 구단에 있어 스포츠 팬 충성도의 개발과 유지는 프로스포츠 운영주체에 매우 중요하게 인식된다(Chae \& Lee, 2000; Hill \& Green, 2000). 따라서 프로스포츠 관중 수의 증가가 정체 중인 근래의 상황에서 스포츠 팬들이 지속해서 경기장 을 찾을 수 있도록 구단이나 리그의 가치를 높이려는 노력이 특히 요구되는 시점이라 할 수 있으며, 이를 위해서는 다 수의 충성스러운 팬을 확보하는 것이 무엇보다 중요하다는 것에 학계와 산업의 의견이 일치하고 있다(Kim, 2004).

충성도가 높은 소비자는 선호하는 제품과 서비스에 대해 깊게 몰입하고 반복적인 구매 성향이 강하게 나타나는데 (Oliver, 1999), 이는 단기간에 걸쳐 일시에 형성되는 것이 아니라 장기간에 걸쳐 형성되기 때문에 소비자의 관심과 흥

\footnotetext{
*This study was supported by the research grant of the KODISA Scholarship Foundation in 2020.

${ }^{* * *}$ Co-Author. Doctoral Student, Department of Sport Convergence, Eulji University, South Korea.

${ }^{* * * * *}$ Corresponding Author. Associate Professor, Department of Sport and Outdoor, Eulji University, South Korea. Email: wonjaeseo@eulji.ac.kr 
미를 지속해서 유발하고, 소비자의 동기를 발현시켜주는 것이 중요한 것으로 보고되고 있다(Son, 2009). 즉 충성도는 스포츠 구단에 강하게 형성된 태도의 결과이므로(Funk \& James, 2006) 스포츠 팬들의 태도에 영향을 미치는 요인을 찾 아내고 관리하는 것이 중요한 과제가 된다. 이와 관련한 선행연구를 살펴보면 스포츠 팬의 충성도에 미치는 선행요인 들을 찾아내고 이의 효율적 관리를 위한 연구가 주를 이루고 있다(Trail \& James, 2001).

그러나 Hong and Son(2010)은 충성도에 관한 그간의 연구가 동일시와 충성도, 팀 브랜드 연상과 충성도에 영향을 미치는 변인 간의 단편적인 관계를 밝히는 것에 제한적이었다고 지적하면서 복합적인 인과관계의 결과로 나타나는 충 성도의 발달과정을 설명하기 위한 체계적인 연구의 필요성을 밝혔다. 이에 Funk \& James(2006)의 수정된 심리적 지속 모델(Revised-Psychological Continuum Model)과 Iwasaki and Havitz(1998)의 관여도, 태도적, 행동적 충성도 간의 관 계 모형을 토대로 관람 소비자의 팀 충성도 발달과정을 검증하고자 하였으며, 충성도는 관람동기, 팀 브랜드 연상, 동일 시, 태도적 충성도, 행동적 충성도의 순서로 순차적으로 발달함을 보였다.

충성도에 관한 다수의 연구 결과에서 확인할 수 있듯이 스포츠에서의 충성도는 스포츠와 관련된 생각, 태도, 동기, 연 상 등에 기반한다(Hong \& Son, 2010). 그런데도 충성도와 관련한 연구의 대다수가 충성도에 영향을 미치는 영향요인 을 탐색하고 그에 따른 관계를 검증하는 데 그치고 있고, 스포츠 팬 개인이 스포츠 구단의 충성스러운 팬이 되어가는 과정에 관한 연구는 부족한 실정이다. 더욱이 현대사회의 첨예한 경쟁과 시장구조의 변화에 따른 기업의 이윤추구와 사회적 책임이라는 양면적 기능의 원활한 수행이 어느 때보다 중요해지고 있는 시점에서 이 같은 문제해결을 위해 중 요하게 다루어야 할 부분이 바로 어떻게 스포츠 팬들에 대한 스포츠 구단의 이미지를 긍정적으로 창출할 수 있을 것인 가이다.

즉 국내 대다수 프로스포츠 구단이 모기업의 홍보와 사회적 기여의 일환으로 운영되고 있다는 점에서 스포츠가 가지 는 정정당당과 선의 이미지를 스포츠 팬에게 심어주기 위해서는 스포츠구단의 사회적 공헌활동을 중요한 경영 요소로 인식할 필요성 있다(Cha, Park, \& Chang, 2020; Lee \& Kim, 2011). 따라서 이러한 관점에서 스포츠 구단의 사회적 활동 에 대한 인식에 따른 충성도의 발달과정을 특징지으려는 연구의 필요성이 제기된다고 하겠다.

이에 본 연구는 프로스포츠 구단에 대한 스포츠 팬의 충성도 발달과정을 검증함에 CSR 활동이 어떠한 기제를 통해 충성도로 발현되는지를 밝히고자 한다. 앞서 살펴본 바와 같이 최근까지 진행된 연구의 대부분이 스포츠 구단의 CSR 활동과 스포츠 팬의 행동에 관한 성과 변수 간의 직접적인 인과관계에만 초점을 맞추고 있다. 그러나 충성도는 스포츠 팬의 다양한 특성과 경험을 통해 나타나는 복합적인 인과관계의 결과이므로 충성도 발달과정을 단순한 변인 간의 관계로 파악하기에는 한계가 존재한다(Hong \& Son, 2010). 따라서 스포츠 구단의 CSR 활동을 통해 이어질 스포츠 팬의 감정적 반응과 행동에 대한 규명이 필요하며, 이에 관한 실증분석을 통해 향후 구단이 전략적 커뮤니케이션의 수단으로 CSR 활동을 수행하고자 할 때 유용한 정보를 제공하는 데 일조하고자 한다. 이러한 연구의 목적을 달성하기 위해 본 연구에서는 Funk and James (2006)의 수정된 심리적 지속모델과 I waski and Havit (1998)의 관여도, 태도적, 행동적 충성도 간의 관계 모형, Hong and Son (2010)의 팀 충성도 발달 과정 모형을 토대로 <Figure 1>과 같이 구단의 CSR 활동을 통한 스포츠 구단 이미지, 동일시, 태도적 충성도, 행동적 충성도 간의 구조적 관계에 관한 연구모형을 제시하고 연구문제를 수립하였다.

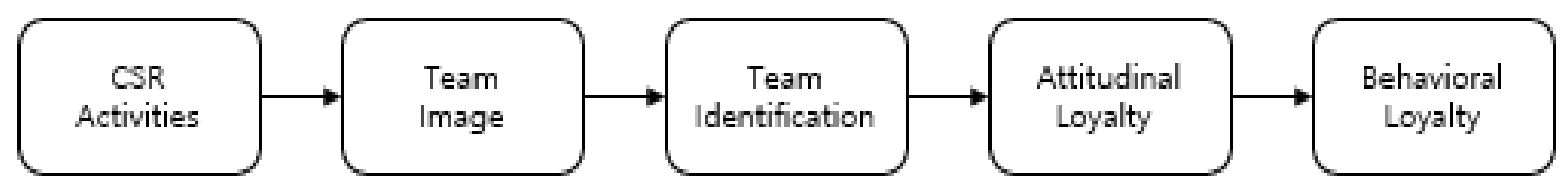

Figure 1: Research model

\section{2. 연구방법}

\section{1. 연구대상}

본 연구는 CSR 활동을 통한 스포츠 구단 이미지, 동일시, 태도적 충성도, 행동적 충성도 간의 구조적 관계를 실증적으 로 검증하고자 국내 4대 프로스포츠 팬을 대상으로 설문조사를 실시하였다. 2018년 3월부터 2019년 2월까지 1년에 걸 쳐 자료 수집이 진행되었으며, 편의표본 추출법을 통해 총 450 부의 설문이 배포되었다. 회수된 설문지 중 불성실 응답, 
무응답 등 분석에 적합하지 않은 표본을 제외한 총 357 부의 자료가 분석에 활용되었다. 최종 연구 대상자의 일반적 특 성은 <Table $1>$ 에 제시된 바와 같다.

\section{2. 조사도구}

본 연구에서 CSR 활동은 스포츠 팬이 지각하는 스포츠 구단의 사회적 책임 활동을 의미한다. CSR 측정은 선행연구에서 사용된 문항을 수정.보완하여 4문항으로 구성하였다 (Mohr \& Webb, 2005; Park \& Chang, 2010; Yoon \& Kim, 2014). 구단 이미지는 스포츠 구단에 대한 스포츠 팬이 가지는 주관적인 신념과 생각, 인상 등을 의미하며, 설문 문항은 기업 이미지의 개념을 토대로 스포츠 분야에 적용된 선행연구의 문항을 바탕으로 구성하였다(Lee, 2018; Lee \& Lee, 2015). 동일시는 스포츠 구단에 대해 스포츠 팬이 감정적으로 몰입함으로써 구단과 자신을 하나로 인식하려는 성향을 의미한다.

Table 1. Demographic characteristics of samples

\begin{tabular}{cccc}
\hline Demographic Categories & & Frequency & $\%$ \\
\hline \multirow{2}{*}{ Gender } & Male & 250 & 70.0 \\
& Female & 107 & 30.0 \\
\hline \multirow{2}{*}{ Age } & 20 's & 253 & 70.9 \\
& 30 's & 78 & 21.8 \\
& Over 40 & 26 & 7.3 \\
\hline \multirow{2}{*}{ Educatoin } & Highschool & 8 & 2.2 \\
& College & 231 & 64.7 \\
& University & 86 & 24.1 \\
& Graduate & 32 & 9.0 \\
\hline \multirow{2}{*}{ Favorite sport } & Basketball & 40 & 11.2 \\
& Volleyball & 30 & 8.4 \\
\hline Total & Baseball & 209 & 58.5 \\
\hline
\end{tabular}

동일시 측정은 선행연구에서 사용된 동일시문항을 수정.보완하여 4개 항목을 구성하였다 (Bhattacharya, Rao, \& Glynn, 1995; Jang, Park, \& Seo, 2017; Kim, 2004). 충성도는 태도적, 행동적 충성도로 구분되는데, 전자는 스포츠 구단 에 대한 팬들의 감정적 몰입과 선호에 관한 심리적 성향을, 후자는 제품 및 서비스를 반복 구매하고자는 실천적 관점에 서의 태도를 의미한다. Funk and James (2006)의 연구와 Yang and Lee (2011), Jang, et, al. (2017)의 연구에서 사용된 충성도문항을 수정.보완하여 각각 4 문항씩으로 구성하였다. 모든 설문문항은 리커트 5 점 척도 $(1=$ 전혀 그렇지 않다, $5=$ 매우 그렇다)를 사용하였으며, 스포츠 경영학 전공 교수 3 인과 박사급 연구원 2인을 대상으로 한 전문가 집단 회의를 통해 내용 타당도를 검증하였다.

\section{3. 자료처리방법}

수집된 자료는 SPSS 23.0 프로그램을 활용하여 통계 처리하였다. 구체적으로 연구대상자의 일반적 특징을 알아보기 위해 빈도분석을 실시하였으며, 측정 도구의 신뢰도와 타당도 검증을 위해 Cronbach's $\alpha$ 계수를 산출하고 확인적 요인 분석을 수행하였다. 또한, 변인 간 상관관계와 다중공선성 유무를 진단하기 위해 상관관계 분석을 하였으며, 수립된 연 구 문제의 검증을 위해 구조방정식 모형 분석을 수행하였다.

\section{3. 연구결과}




\section{1. 측정도구의 신뢰도 및 타당도 검증}

본 연구에서 사용된 측정 문항의 신뢰도와 타당도를 검증하기 위해 신뢰도 분석과 확인적 요인분석을 하였다(Table 2). 측정모형의 적합도는 $\chi 2=442.170(\mathrm{p}<.001), \mathrm{df}=142, \mathrm{CMIN} / \mathrm{df}=3.114, \mathrm{RMR}=.065, \mathrm{CFI}=.916, \mathrm{RMSEA}=.077$ 으로 전반 적인 평가 기준을 상회하는 것으로 나타났다. 신뢰도 분석 결과, 모든 요인이 일반적 요구 기준치인 .7 이상을 충족하는 것으로 확인하였으며(Nunnally \& Bernstein, 1994), 잠재변인의 개념신뢰도(Construct Reliability: CR) 또한 .7를 상회 하는 것으로 나타나 구성개념의 집중타당성이 확보되었다(Anderson \& Gerbing, 1988). 다음으로 판별 타당성 검증을 위해 분산추출지수(Average Variance Extracted: AVE)를 산출한 후 이를 상관계수의 제곱 값과 비교하는 절차를 수행하 였다<표 3>. 우선 각 변수의 AVE값은 기준치인 .5를 상회하고, 상관계수의 제곱값이 AVE를 초과하지 않는 것으로 나타 나 판별타당성이 확인되었다(Fornell \& Larcker, 1981).

Table 2. Confirmatory Factor Analysis

\begin{tabular}{|c|c|c|c|c|c|c|}
\hline Variables & Items & $\begin{array}{l}\text { Standardized } \\
\text { Estimates }\end{array}$ & S.E. & $\mathbf{t}$ & Cronbach's $\alpha$ & CR \\
\hline \multirow{4}{*}{$\begin{array}{c}\text { CSR } \\
\text { Activities }\end{array}$} & Item1 & .728 & - & - & \multirow{4}{*}{.874} & \multirow{4}{*}{.878} \\
\hline & Item2 & .819 & .072 & $14.947 * * *$ & & \\
\hline & Item3 & .904 & .074 & $16.247 * * *$ & & \\
\hline & Item4 & .751 & .069 & $13.725^{* * *}$ & & \\
\hline \multirow{3}{*}{$\begin{array}{l}\text { Team } \\
\text { Image }\end{array}$} & Item1 & .763 & - & - & \multirow{3}{*}{.794} & \multirow{3}{*}{.802} \\
\hline & Item2 & .829 & .075 & $13.759 * * *$ & & \\
\hline & Item3 & .677 & .084 & $11.878^{* * * *}$ & & \\
\hline \multirow{4}{*}{$\begin{array}{c}\text { Team } \\
\text { Identification }\end{array}$} & Item1 & .716 & - & - & \multirow{4}{*}{.775} & \multirow{4}{*}{.822} \\
\hline & Item2 & .588 & .088 & $10.186 * * *$ & & \\
\hline & Item3 & .847 & .097 & $14.012^{* * *}$ & & \\
\hline & Item 4 & .763 & .092 & $13.021 * * *$ & & \\
\hline \multirow{4}{*}{$\begin{array}{l}\text { Attitudinal } \\
\text { Loyalty }\end{array}$} & Item1 & .778 & - & - & \multirow{4}{*}{.882} & \multirow{4}{*}{.883} \\
\hline & Item2 & .830 & .073 & $16.329 * * *$ & & \\
\hline & Item3 & .847 & .075 & $16.687 * * *$ & & \\
\hline & Item4 & .777 & .065 & $15.159^{* * *}$ & & \\
\hline \multirow{4}{*}{$\begin{array}{c}\text { Behavioral } \\
\text { Loyalty }\end{array}$} & Item1 & .662 & - & - & \multirow{4}{*}{.818} & \multirow{4}{*}{.821} \\
\hline & Item2 & .716 & .105 & $11.332 * * *$ & & \\
\hline & Item3 & .845 & .108 & $12.609^{* * *}$ & & \\
\hline & Item4 & .694 & .103 & $11.057 * * *$ & & \\
\hline
\end{tabular}

Note. $* * * \mathrm{p}<.001$

\section{2. 상관관계 분석 결과}

본 연구의 각 변인 간 상관관계와 다중공선성 유무를 진단하기 위해 상관관계 분석을 수행한 결과는 <Table $3>$ 에 제 시된 바와 간다. 분석 결과, 모든 변인 간에는 유의미한 상관관계가 존재하는 것으로 나타났고, 다중공선성이 의심되는 관계는 존재하지 않는 것으로 판명되었다. 
Table 3. Correlation Analysis

\begin{tabular}{llccccc}
\hline \multicolumn{1}{c}{ Variables } & \multicolumn{1}{c}{ Mean } & $\mathbf{1}$ & $\mathbf{2}$ & $\mathbf{3}$ & $\mathbf{4}$ & $\mathbf{5}$ \\
\hline CSR Activities & 3.46 & & & & \\
Team Image & 3.81 & .624 &. & & \\
Team Id & 3.30 & .451 & .459 &. & \\
Attitudinal Loyalty & 3.90 & .381 & .409 & .537 & & .563 \\
Behavioral Loyalty & 3.11 & .352 & .155 & .557 & \\
\hline
\end{tabular}

\section{3. 연구모형 검증 결과}

스포츠 구단의 CSR 활동에 따른 팬충성도의 발달 과정을 분석하기 위해 최대우도법(Maximum Likelihood Estimation)을 통한 구조방정식 모형 분석을 수행하였으며, <Table 4>와 같이 연구모형의 적합성 지수는 비교적 양호 한 수준으로 확인되었다. 변인 간 관계 및 영향력 검증 결과, CSR 활동은 구단 이미지에 영향을 미치며, 구단 이미지는 동일시에 영향을 미치는 것으로 나타났다. 또한, 동일시는 태도적 충성도에 영향을 미치며, 태도적 충성도는 이어서 행 동적 충성도에 영향을 미치는 것으로 나타났다. 이상의 결과에서 확인할 수 있듯이 스포츠 구단 충성도 발달과정 검증 을 위해 설정한 모형의 모든 변인 간 관계가 유의미한 것으로 나타나 본 모형이 프로야구 구단의 CSR 활동에 따른 충 성도 발달과정을 설명하는 데 적합한 것으로 확인되었다.

Table 4. Testing Final Model

\begin{tabular}{ccccc} 
Paths & $\begin{array}{c}\text { Unstandardized } \\
\text { Coefficients }\end{array}$ & $\begin{array}{c}\text { Standardized } \\
\text { Coefficients }\end{array}$ & Error & t \\
\hline CSR $\rightarrow$ Image & 651 & .644 & .069 & $9.394^{* * * *}$ \\
Image $\rightarrow$ Identification & 532 & .518 & .069 & $7.664^{* * *}$ \\
Identification $\rightarrow$ Attitudinal & 554 & .583 & .062 & $8.877^{* * * *}$ \\
Attitudinal $\rightarrow$ Behavioral & 623 & .591 & .072 & $8.606^{* * *}$ \\
\hline
\end{tabular}

$\chi 2=512.922(\mathrm{p}<.001), \mathrm{df}=148, \mathrm{CMIN} / \mathrm{df}=3.466, \mathrm{RMR}=.097, \mathrm{CFI}=.897, \mathrm{RMSEA}=.083 . * * * \mathrm{p}<.001$

Note. $* * * \mathrm{p}<.001$

\section{4. 논의 및 결론}

본 연구에서는 프로스포츠 구단의 CSR 활동이 어떠한 기제를 통해 충성도로 발현되는지를 검증하고자 하였다. 그 결과, CSR 활동에 따라 구단 이미지, 동일시, 태도적 충성도, 행동적 충성도로 이어지는 발달과정을 확인할 수 있었다. 이를 구체적으로 논의하면 다음과 같다.

첫째, 프로스포츠 구단의 CSR 활동은 구단 이미지에 긍정적인 영향을 미치는 것으로 나타났다. 즉, CSR 활동이 스포츠 팬이 인식하는 스포츠 구단에 대한 이미지를 관리하고 강화하는데 유용한 수단이 될 수 있음을 보여준다. 이는 CSR 활동을 통해 기업의 이미지를 제고할 수 있음을 밝힌 다수의 선행연구를 지지하는 결과이다(An \& Han, 2014; Kim \& Lim, 2010; Martínez, Pérez, \& del Bosque, 2014; Yoo \& Chun, 2008;). 최근 선수와 구단이 초래한 부정적 이슈로 인한 팬들의 실망감과 그로 인한 스포츠 구단의 이미지가 하락하고 있기에 이러한 위기상황을 적절히 대처할 수 있는 전략적 커뮤니케이션이 요구된다 하겠으며, 본 연구의 결과에 비추어 볼 때, 스포츠 구단은 CSR 활동을 수행함으로써 
스포츠 팬들로 하여금 구단의 이미지를 제고하는 방법을 모색해 볼 수 있을 것이다. 다시 말해, 마케팅 활동을 통한 스포츠 구단의 이미지 개선 외에도 윤리경영의 한 부분으로써 스포츠 구단이 CSR 활동을 스포츠 팬에게 잘 인식시키는 것이 중요하여 이를 위한 커뮤니케이션 전략을 개발하기 위한 노력이 필요로 함을 시사한다.

둘째, 스포츠 구단의 이미지는 구단 동일시에 긍정적인 영향을 미치는 것으로 나타났다. 이는 스포츠팀의 이미지가 팀 동일시에 영향을 미친다는 다수의 선행연구와 맥을 같이 하고 있다(Kim, 2010; Kim \& Chang, 2004). 이에 관해 Kim and $\operatorname{Kim}(2012)$ 은 구단에 동일시된 관중이 구단의 제품과 서비스를 지속적으로 구매한다면서 따라서 긍정적인 구단의 이미지를 형성하기 위해 관중들이 스포츠 구단에 원하는 이미지를 정확히 파악하고 분석하는 것이 중요함을 밝혔다. 앞서 언급한 바와 같이 가치 지향적인 소비로의 전환이 이루어짐에 따라 스포츠 구단 역시 어떤 상품을 만들 것인가 아닌 어떻게 상품을 만들고 서비스할 것인지에 관한 깊이 있는 고민이 필요할 것이며, 그러한 방법의 하나로서 본 연구의 결과와 같이 CSR 활동을 적극적으로 수행한다면 이를 통해 제고된 이미지를 바탕으로 스포츠 팬의 높은 동일시를 이끌 수 있을 것으로 예상해 볼 수 있다.

셋째, 구단 동일시는 태도적 충성도에 긍정적인 영향을 미치며, 태도적 충성도는 다시 행동적 충성도에 영향을 미치는 것으로 나타났다. 이는 Bhattachary, et, al.(1995)의 연구를 통해 입증된 특정 기업에 대한 동일시가 해당 기업이 판매하는 제품과 서비스의 구매행동에 영향을 미친다는 주장을 뒷받침하고 있다. Hur and Kim(2009)와 Kim and $\operatorname{Kim}(2012)$ 의 연구에서도 스포츠 소비자의 구단에 대한 높은 동일시가 구단의 충성도에 영향을 미치는 것으로 나타나 본 연구의 결과를 지지하고 있다. 따라서 스포츠 구단은 스포츠 팬의 동일시를 확립하고 높이기 위한 다양한 전략을 모색해야 하며, 이는 스포츠 구단이 스포츠 팬과 함께한다는 인식을 심어 주는 것이 중요하므로 스포츠 팬이 중요시하게 여기는 평상시의 가치관에 관한 조사와 탐구가 이루어질 필요성이 존재하며, CSR 활동과 같은 윤리적인 경영 활동에 관해서 적극적인 홍보를 통해 긍정적인 효과를 획득할 수 있을 것이다. 한편, 태도적 충성도가 행동적 충성도에 영향을 미치는 것으로 나타났는데, 이에 관하여 Hong and Son(2010)은 스포츠 팬의 욕구와 기대수준에 부합하는 마케팅 전략이 필요하며, 스포츠 팬의 태도적 측면에 초점을 맞춘 마케팅 전략과 더불어 행동적 충성도를 강화할 수 있는 촉진 방향이 고려되어야 함을 주장하였다. 이러한 견해에 비추어 볼 때, 스포츠 구단은 CSR 활동에 스포츠 팬을 함께 참여시킴으로써 스포츠 구단뿐만 아니라 스포츠 팬의 윤리적 성향을 고취할 수 있을 것이며, 이를 통한 긍정적 감정과 이미지를 함께 향유함으로써 결국 스포츠 구단에 대한 충성스러운 팬으로 만들 수 있을 것이다.

끝으로 본 연구는 프로스포츠 구단의 CSR 활동이 어떠한 기제를 통해 충성도로 발현되는지를 검증하는 데 목적을 두었다. 최근까지 진행된 연구의 대부분이 스포츠 구단의 CSR 활동과 스포츠 팬의 행동에 관한 성과 변수 간의 직접적인 인과관계에만 초점을 맞추고 있었으나 충성도는 스포츠 팬의 다양한 특성과 경험을 통해 나타나는 복합적인 인과관계의 결과이므로 충성도 발달과정을 단순한 변인 간의 관계로 파악하기에는 한계가 존재했다. 따라서 스포츠 구단의 CSR 활동을 통해 이어질 스포츠 팬의 감정적 반응과 행동에 대한 규명을 본 연구에서 수행함으로써 향후 구단이 전략적 커뮤니케이션의 수단으로 CSR 활동을 수행하고자 할 때 유용한 정보를 제공하는 데 일조하고자 하였다. 그러나 본 연구는 4 대 프로스포츠 종목을 통합하여 조사를 진행하였기에 각 종목과 개별 스포츠 구단의 특성을 온전히 반영하고 있지 못한 한계를 가진다. 이와 관련한 스포츠 팬들의 성향도 달라질 수 있으므로 향후 연구에서는 이러한 부분을 고려한 연구 설계와 조사를 통해 살펴보는 것도 의미가 있을 것으로 판단한다. 또한, 프로스포츠 구단뿐만 아니라 개별 스포츠 종목의 선수들을 대상으로 하여 스폰서십이나 인도스먼트에 대하여 스포츠 소비자가 지각하는 일체성 또는 충성도의 발달과정도 흥미로운 연구 주제가 될 수 있을 것으로 기대한다.

\section{References}

An, S. Y., \& Han, J. S. (2014). A Study on the effects of corporate social responsibility hotel image, customer satisfaction and customer loyalty. Journal of Tourism \& Leisure Research, 26(4), 101-120.

Anderson, J. C., \& Gerbing, D. W. (1988). Structual equation modeling in practice: A review and recommend two-step approach. Psychological Bulletin, 103(3), 411-423.

Bhattacharya, C. B., Rao, H., \& Glynn, M. A. (1995). Understanding the bond of identification: An investigation of its correlates among art museum members. Journal of marketing, 59(4), 46-57.

Cha, J. H., Park, P., \& Chang, K. R. (2020). Relationship among Professional Sports Team's Ethical Management, Team Identification and Fan Loyalty, Korean journal of physical education, 53(1), 191-207.

Chae, H. S., \& Lee, J. H. (2000). An Investigation of Factors Related to Sport Fan Behavior Influencing Attendance at Korean Professional Sports, Korean Journal of Sport Management, 5(2), 137-154. 
Fornell, C., \& Larcker, D. F. (1981). Structural equation models with unobservable variables and measurement error: Algebra and statistics. Journal of Marketing Research, 18(3), 382-388.

Funk, D. C., \& James, J. D. (2006). Consumer loyalty: The meaning of attachment in the development of sport team allegiance. Journal of Sport Management, 20(2), 189-217.

Hill, B., \& Green, B. C. (2000). Repeat attendance as a function of involvement, loyalty, and the sportscape across three football contexts. Sport management review, 3(2), 145-162.

Hong, S. P., \& Son, S. B. (2010). Analysis of Professional Baseball Spectator`s Team Allegiance Development Process Model, Korean Journal of Sport Management, 15(6), 83-96.

Hur, J., \& Kim, Y. M. (2009). The effect of company's reputation, credibility, and familiarity of sports goods companies on company identification, attitude toward brand, and Loyalty. The Korean Journal of Physical Education, 48, $277-289$.

Iwasaki, Y., \& Havitz, M. E. (1998). A path analytic model of the relationships between involvement, psychological commitment, and loyalty. Journal of leisure research, 30(2), 256-280.

Jang. J., Park, H. Y., \& Seo, H. M. (2017). The Structural Relationship among Team Image, Team Identification and Attitudinal Behavioral Loyalty of Professional Soccer Teams, Journal of Sport and Leisure Studies, 70, 63-76.

Kim, Y. M. (2004). The Relationship among Attribute of Professional Football Team, Team Identification, and Team Loyalty. Korean journal of physical education, 43(6), 623-631.

Kim, Y. M. (2010). The effect of spectating value of professional baseball on satisfaction with spectating, attitude toward a team, team image, team identification, \& intention of revisit. Korean Journal of Sport Science, 21(4), 1569-1581.

Kim, B. R., \& Lim, S. J. (2010). The influence of professional sports teams' cause-related marketing (CRM) and corporate social responsibility (CSR) on the corporation image, fan loyalty, and marketing performance. Korean Journal of Sports Science, 19(2), 833-844.

Kim, H. J., \& Lee, H. Z. (2009). The Effect of the Well-being Consumer Value Orientations, the Perceived Value and Brand Preference on Purchase Intention of the Environment-friendly Cosmetic. Journal of The Korean Society of cosmetology, 15(1), 327-341.

Kim, S. W., \& Chang, K. R. (2004). The impact of identification with university sport team and majoring department on identification and loyalty with university. The Korean Journal of Physical Education, 43(4), 545-554.

Kim, Y. M., Kim, S. Y., (2012), The structural relationship between relationship between a professional basketball club and spectators, club image, club identification, parent company identification, parent company attitude and parent company loyalty, Korean Journal of Sport Management, 17(3), p13-26.

Lee, D. J. (2018). Structural relationship among Marketing Activity, Team Image, Team Satisfaction, Team Identification and Behavioral Intention of Professional Football Clubs. Korean Journal of Sports Science 27(2), 397-410.

Lee, H. S., \& Lee, T. Y. (2015). Structural Relationship between of professional baseball club Integrated sMarketing Communication(IMC) activities on its club image, customer satisfaction and customer loyalty. Korean Journal of Sports Science 24(3), 775-788.

Lee, J. H., \& Kim, W. K. (2011). An Importance-Satisfaction Analysis on Corporate Social Responsibility of Pro-Baseball Team thorough an IPA Method, Korean Journal of Sport Science, 22(2), 1986-1998.

Martínez, P., Pérez, A., \& Del Bosque, I. R. (2014). CSR influence on hotel brand image and loyalty. Academia Revista Latinoamericana de Administración.

Mohr, L. A., \& Webb, D. J. (2005). The effects of corporate social responsibility and price on consumer responses. Journal of consumer affairs, 39(1), 121-147.

Nunnally, J. C., \& Bernstein, I. H. (1994). Validity. Psychometric theory, 3, 99-132.

Oliver, R. L. (1999). Whence consumer loyalty?. Journal of marketing, 63(4), 33-44.

Park, S. Y., \& Chang, K. R. (2010). A Study of the Fit Perceptions of Corporate Social Responsibility by Professional Sport Teams on Sport Fan Attitudes and Behavioral Intentions. Korean Journal of Sport Science, 21(3), 1417-1430.

Son, S. B. (2009). An examination of the Loyalty development process of professional basketball consumers, Korean journal of physical education, 48(1), 185-196.

Trail, G. T., \& James, J. D. (2001). The motivation scale for sport consumption: Assessment of the scale's psychometric properties. Journal of sport behavior, 24(1).

Yang, J. C., \& Lee, G. C. (2011). The Effects of Professional Sports Team`s Sports Ethics Management on Team`s Reputation and Loyalty. Journal of Sport and Leisure Studies, 43, 451-462.

Yoo, Y. S., \& Chun, J. Y. (2008). Relationship between the residents' attitude toward professional basketball team's social philanthropy and team image, team identification, and team Loyalty. The Korean Journal of Physical Education, 47(4), 187-199.

Yoon, N. S., \& Kim, Y. E. (2014). The Distribution Industry’s Social Responsibility and Ethics Management: Effects on Corporate Trust and Loyalty. Journal of Distribution Science, 12(7), 23-35. 